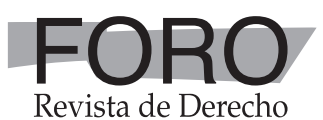

\title{
Discriminación e igualdad: el matrimonio igualitario en la Opinión Consultiva OC-24/17 Corte IDH en Ecuador
}

Discrimination and equality: Equal marriage in Advisory Opinion OC-24/17 of the Inter-American Court in Ecuador

\section{Pedro Páez Bimos}

Docente Universidad Metropolitana del Ecuador

ppaez@corp-defense.com

ORCID: 0000-0003-4951-307X

DOI: https://doi.org/10.32719/26312484.2019.32.2

Fecha de recepción: 4 de febrero de 2019

Fecha de aceptación: 22 de agosto de 2019 


\section{RESUMEN}

La Opinión Consultiva OC-24/17 de la Corte Interamericana de Derechos Humanos es de gran importancia para la región pues trata temáticas paradigmáticas como la identidad de género, igualdad y no discriminación a parejas del mismo sexo. Este es el punto central de reflexión en el presente ensayo, en el que se estudiará el principio de igualdad y no discriminación a las personas sexo-genéricas diversas y el marco del matrimonio igualitario, tomando en cuenta el contexto discriminatorio reciente que se ha venido dando al ser una minoría poco o nada protegida por el Estado ecuatoriano.

Palabras Clave: Derechos Humanos; Corte Interamericana de Derechos Humanos; Sistema interamericano de Derechos Humanos; matrimonio igualitario.

\section{ABSTRACT}

Advisory Opinion OC-24/17 of the Inter-American Court of Human Rights is of great importance to the region on paradigmatic issues such as gender identity, equality and non-discrimination for same-sex couples. This is the central point of reflection in the present essay, in which the principle of equality and non-discrimination to diverse sex-generic persons and the framework of equal marriage as a human right will be studied. Taking account, the discrimination of recent history that has been given to a minority little or nothing protected by the State.

KeYwords: Human Rights; Inter-American Court of Human Rights; Inter-American Human Rights System; equal marriage.

\section{INTRODUCCIÓN}

L

a importancia de la opinión consultiva OC-24/17 de la Corte Interamericana de Derechos Humanos es relevante para la protección, garantía y reconocimiento de las minorías sexo-genéricas diversas que han sido históricamente discriminadas por el Estado, por particulares y, en general, por los diversos sistemas de gobierno. En este caso establece una interpretación amplia y de obligatorio cumplimiento para todos los Estados parte del Sistema Interamericano, que busca reconocer puntos fundamentales de la sociedad y reconstruir el aspecto jurídico de la identidad de género, igualdad y la no discriminación a parejas del mismo sexo, con la finalidad de romper con los viejos atavismos de fuente conservadora, y dar paso a la evolución jurídico-normativa de la sociedad actual. 
Es motivo del presente trabajo revisar dos puntos clave, entre los muchos abordados por la Corte IDH, que tratan el principio de igualdad y no discriminación, así como la postura que tiene la Corte sobre el matrimonio igualitario y los diferentes escenarios que se han venido dando en el panorama nacional. No obstante, son evidentes las diferentes dificultades en la aplicación en el derecho interno de los diferentes Estados parte, lo cual es motivo de crítica y reflexión de los funcionarios del sector público y los particulares, dificultando el cumplimiento con las disposiciones establecidas en la presente opinión consultiva de la Corte IDH y la aplicación directa de la normativa constitucional que tiene el Estado ecuatoriano en conjunto con la reciente sentencia n. ${ }^{\circ} 11-18-\mathrm{CN} / 19$ de la Corte Constitucional.

\section{INSTRUMENTOS INTERNACIONALES Y CONTEXTO HISTÓRICO SOBRE LA IGUALDAD Y NO DISCRIMINACIÓN RESPECTO A LAS PERSONAS SEXO-GENÉRICAS DIVERSAS EN EL CASO ECUATORIANO}

Para dar contexto a la presente discusión es imprescindible mencionar que, dentro del aspecto internacional de los Derechos Humanos, existe un número importante de instrumentos que buscan proteger los derechos de las personas o grupos de personas más vulnerables dentro del contexto internacional para el acceso igualitario y a la no discriminación de sus derechos. Y, aunque no es tarea fácil, existe un cierto consenso en algunos organismos como Naciones Unidas y sus convenciones; tal es el caso de la Declaración Universal de Derechos Humanos que en su artículo 7 establece como derecho a la igual protección y no discriminación de los derechos que reconoce, incluyendo en su artículo 23 la no discriminación respecto a la igualdad al trabajo y remuneración a todas las personas. Otro caso es lo que establece la Convención sobre la Eliminación de Todas las Formas de Discriminación contra la Mujer, ratificada por el Ecuador en 1981 (CEDAW). Ya dentro de un grupo más específico de personas, establece en su artículo 1 una relación de lo que se entiende por discriminación contra la mujer como:

distinción, exclusión o restricción basada en el sexo que tenga por objeto o resultado menoscabar o anular el reconocimiento, goce o ejercicio por la mujer, independiente mente de su estado civil, sobre la base de la igualdad del hombre y la mujer, de los derechos humanos y las libertades fundamentales en las esferas política, económica, social, cultural y civil o en cualquier otra esfera, por lo que nos da ciertas pautas para identificar que la discriminación se da por la distinción, exclusión o restricción, cuestión que ya se abordó 
con anterioridad por Naciones Unidas en la Convención Internacional sobre la Eliminación de todas las Formas de Discriminación Racial de $1965 .{ }^{1}$

A pesar de la ausencia de una convención determinada en el caso de la discriminación de las personas sexo-genéricas diversas, ya se ha planteado en los denominados "Principios de Yogyakarta" o "Principios sobre la aplicación de la legislación internacional de derechos humanos con relación a la orientación sexual y la identidad de género", ${ }^{2}$ una continuación de la Declaración Universal de los Derechos Humanos, dentro de la línea progresiva que tienen. En este documento creado y ratificado por expertos reconocidos se establecen algunos principios relevantes para el disfrute de los Derechos Humanos, el reconocimiento de la personalidad jurídica a la vida, privacidad, seguridad, entre otros, pero, sobre todo, su segundo principio que reconoce la igualdad y no discriminación por motivos de orientación sexual o identidad de género. Estos principios son relevantes y generan un ámbito de protección especial a grupos que han sido vulnerados de manera reiterada a lo largo de la historia, tanto por particulares como por la institucionalidad pública.

En el ámbito ecuatoriano, el país ha tenido una posición conservadora respecto a la homosexualidad y las personas sexo-genéricas diversas, criminalizándolas por su elección personal. En el ámbito histórico-penal ha estado presente la tipificación de esta conducta desde el Código Penal de 1937, que sancionaba en su artículo 401 la sodomía (penetración anal), pasando al Código Penal de 1938 como homosexualismo, ya no como sodomía, hasta el penúltimo código que estableció este tipo penal en su artículo 516. ${ }^{3}$ Las movilizaciones y los reclamos por parte de los grupos de personas sexo-genéricas diversas por la persecución de los agentes de policía eran reiteradas, siendo un detonante de dichas manifestaciones la detención masiva en 1997 de más de cien personas "homosexuales". Fue en ese momento cuando las marchas y la presión por parte de los primeros colectivos LGBTI iniciaron su lucha por el reconocimiento de que la homosexualidad no era ni delito ni enfermedad; la penalización de la homosexualidad es contraria a los derechos constitucionales; y los derechos sexuales son derechos humanos. ${ }^{4}$

1. En esta Convención ya el artículo 1 y 2 adoptaban los conceptos de discriminación racial y los mecanismos a implementar por los Estados parte.

2. Consejo de Derechos Humanos de las Naciones Unidas, "Principios de Yogyakarta", Panel Internacional de Especialistas en Legislación Interna de Derechos Humanos y Orientación Sexual e Identidad de Género, 26 de marzo de 2007, 〈http://www.oas.org/dil/esp/orientacion_sexual_Principios_de_Yogyakarta_2006.pdf〉.

3. Javier Aguiar Román, "Historia legal de la homosexualidad en el Ecuador", Revista Novedades Jurídicas, n. ${ }^{\circ} 146$ (2018): 53.

4. Ibíd., 54-5. 
La prensa recoge que agrupaciones como la Fundación de Acción y Ayuda para la Prevención del Sida (FEDAEPS) presentaron varias quejas en 1994 ante la Organización de Estados Americanos en la que se denunciaba la vulneración de los derechos humanos de los grupos LGBTI. ${ }^{5}$ Existen varias historias sobre el maltrato, abuso y denigración que recibían varias personas por tener una preferencia contraria al paradigma moral religioso, las cuales eran repetidas en todo el Ecuador antes de las posteriores reformas en el ámbito punitivo. ${ }^{6}$

Sin embargo, la persistencia de estos grupos los llevó a la interposición de acciones constitucionales para exigir el reconocimiento a su igualdad y no discriminación. No fue hasta 1997 que el Tribunal Constitucional, mediante Resolución n. ${ }^{\circ}$ 106, publicada en el Registro Oficial Suplemento 203 de 27 de noviembre de 1997, declaró inconstitucional la primera parte del artículo 516, permitiendo que la criminalización de la homosexualidad sea de una vez por todas eliminada del aparataje punitivo estatal.

En la Constitución del año 1998 se reconoció en su artículo 23.3 la igualdad ante la ley a todas las personas sin distinción de su orientación sexual, siendo un hito histórico para los grupos LGBTI. ${ }^{7}$ Esta cuestión que fue confirmada en la actual Constitución del año 2008 en su artículo 11.2, además de añadir la obligación al Estado de adoptar acciones afirmativas para promover una realidad más igualitaria de carácter real. ${ }^{8}$

En el año 2019, con una renovada Corte Constitucional, se recogió, mediante sentencia $\mathrm{n}^{\circ}$ 11-18-CN/19 sobre el matrimonio igualitario, en la que figuró como juez ponente Ramiro Ávila Santamaría, con especial énfasis lo dispuesto en la opinión consultiva OC-24/17 y sustentando que no existe contradicción en el texto constitucional en torno al matrimonio entre hombre y mujer, y personas del mismo sexo, sino

5. El Telégrafo, "Homosexualidad era castigada con 8 años de prisión en década del 90", El Telégrafo, 2 de diciembre de 2016.

6. Un ejemplo de estas situaciones fue lo vivido por Gina, quien, por su preferencia sexual y su modo de vestir, fue insultada, abusada y agredida por varios años. "Cuando ser gay era un delito", El Diario, 5 de diciembre de 2017.

7. Ecuador, Constitución de la República del Ecuador, Registro Oficial 1, 11 de agosto de 1998, art. 23. En el citado artículo se establece que "Art. 23.- Sin perjuicio de los derechos establecidos en esta Constitución y en los instrumentos internacionales vigentes, el Estado reconocerá y garantizará a las personas los siguientes: [...] 3. La igualdad ante la ley. Todas las personas serán consideradas iguales y gozarán de los mismos derechos, libertades y oportunidades, sin discriminación en razón de nacimiento, edad, sexo, etnia, color, origen social, idioma, religión, filiación política, posición económica, orientación sexual; estado de salud, discapacidad, o diferencia de cualquier otra índole [...]".

8, Ecuador, Constitución de la República del Ecuador, Registro Oficial 449, 20 de octubre de 2008, art. 11. En el citado artículo se establece que "Art.11.2 [...] El Estado adoptará medidas de acción afirmativa que promuevan la igualdad real en favor de los titulares de derechos que se encuentren en situación de desigualdad $[\ldots] "$.. 
una complementariedad; por tanto permitiendo el ejercicio del derecho al matrimonio igualitario, lo cual revisaremos con mayor amplitud más adelante.

Para la fundamentación de la sentencia se observaron los diferentes amicus curiae que tuvieron la oportunidad de expresarse, aportando con la pluralidad necesaria de un proceso con dichas características. Fue relevante el amicus presentado por De justicia que la Corte lo tomó con mucha importancia al establecer la necesaria separación que debe existir entre procreación y matrimonio desde la perspectiva jurídica de la autonomía de la voluntad ${ }^{9}$ o el aporte del Consejo Nacional para la Igualdad de Género que fundamentó la idea de que la orientación sexual de las personas le da sentido a su propia existencia individual, siendo obligación del Estado garantizar su respeto y protección. ${ }^{10}$

Antes, durante y después de la decisión tomada por la Corte Constitucional ecuatoriana, se generó un ambiente de tensión social que se caracterizó por la manifestación pública de diferentes sectores, en especial de los sectores más conservadores y católicos de la sociedad, ${ }^{11}$ cuestión esperada tratándose de un fallo que busca de manera cierta un progreso en materia de derechos humanos para la realidad ecuatoriana.

Una vez contextualizada la discusión, es pertinente revisar cuáles fueron los principales argumentos que se encuentran en la opinión consultiva OC-24/17 de la Corte Interamericana de Derechos Humanos.

\section{DESARROLLO PROGRESIVO: IGUALDAD Y NO DISCRIMINACIÓN BAJO EL ENFOQUE DE LAS PERSONAS SEXO-GENÉRICAS DIVERSAS}

La dialéctica jurídica en los países con tradición occidental ha cambiado a lo largo de la historia. Los preceptos jurídicos, instituciones y normativa que se han creído sólidos e incuestionables con el tiempo cambiaron y se han podido desarrollar, en algunas circunstancias, a favor de los sectores más vulnerables de la sociedad, y, en otras ocasiones, a favor de los sectores tradicionalmente opresores del poder políticoeconómico. Por ejemplificar en otros ámbitos, existe también un desarrollo progresivo con otros tipos de derechos, tal es el caso del establecimiento de los Derechos Humanos, su internacionalización y el desarrollo progresivo de los derechos económicos,

9. Ecuador Corte Constitucional, "Sentencia", en Caso n. ${ }^{\circ} 11-18-C N, 12$ de junio de 2019, 22.

10. Ibíd., 38.

11. Andrés Donoso Loor, “Convocan nuevas marchas contra el matrimonio civil igualitario en Ecuador”, $E l$ Universo, 19 de junio de 2019. 
sociales, culturales y colectivos ${ }^{12}$ cuestión que demuestra que los Derechos Humanos paulatinamente tienen otros rumbos de protección.

Y, bajo esta misma lógica de expansión en la protección de derechos, no solo los DESC han tenido cobertura, sino también otros derechos como la igualdad y no discriminación de las personas sexo-genérica diversas que corresponden a los derechos civiles. Si revisamos el Pacto Internacional de Derechos Civiles y Políticos, ${ }^{13}$ encontramos artículos como el 16 y 23, que establecen que aquellos son derechos inherentes a la persona humana, y que deben ser reconocidos por los diferentes Estados parte, siendo signatario en este caso el Ecuador. Es así como el matrimonio civil debe ser comprendido en su contexto histórico y dialéctico; es bien conocido que sus inicios se dieron por parte del matrimonio canónico; sin embargo, con el avanzar del tiempo existió una separación entre el Estado y la iglesia -a efectos administrativos, políticos, jurídicos, entre otros-, permitiendo que la noción de matrimonio civil exista y se perciba como una institución democrática regida por el Derecho, la libertad y la igualdad de los contrayentes. ${ }^{14}$ Es innegable que el ejercicio del poder público ha tenido una directa vinculación con el predominio de la orientación heterosexual, apoyada por concepciones religiosas y de los gobernantes del momento, en un claro rechazo y conflicto contra la diversidad sexual. ${ }^{15}$ Por tanto, es importante establecer que este derecho civil no pueda ser negado bajo una fundamentación que, en apariencia, busque regresar a construcciones valorativas de la retórica canónica.

Una expresión de este poder es la creación de normativa que limita el desenvolvimiento de la libre autonomía de elegir con quien compartir sentimientos y el desarrollo de la vida. Sin embargo, con el pasar del tiempo, y tras muchas luchas ejercidas por las personas sexo-genéricas diversas, se han podido establecer claras construcciones jurídicas a nivel nacional e internacional, así como precedentes importantes en la búsqueda que les permita tener una situación de igualdad real y no aparente, ${ }^{16}$ tal como revisamos algunos hechos con anterioridad.

12. Pedro Nikken, "La protección de los derechos humanos: haciendo efectiva la progresividad de los derechos económicos, sociales y culturales”, Revista IIDH, vol. 5 (2010): 66.

13. ONU Asamblea General, Pacto Internacional de Derechos Civiles y Políticos, 19 de diciembre de 1976.

14. Abraham Barrero, "El matrimonio entre ciudadanos del mismo sexo: ¿Derecho fundamental u opción legislativa?", Revista de Estudios Politicos. Nueva Época, n. ${ }^{\circ} 163$ (2014): 42-3.

15. Josefina Alventosa del Río, Discriminación por orientación sexual e identidad de género en el derecho español (Madrid: Ministerio de Trabajo y Asuntos Sociales, 2008), 35-6.

16. Como se indicó en el caso ecuatoriano, con la despenalización de la homosexualidad que estableció el Código Penal anterior el 25 de noviembre de 1997 o el reconocimiento de la unión de hecho entre personas del mismo sexo en el año 2014. 
La opinión consultiva 24/17 en su título VI establece ciertas líneas importantes sobre la igualdad y no discriminación a las personas LGBTI, las cuales revisaremos a continuación. Aunque no existe un concepto definido en instrumentos como el Pacto Internacional de Derechos Civiles y Políticos, existen ciertos convenios posteriores que dan una noción de discriminación para circunstancias especiales, como en el ámbito de adultos mayores o las mujeres. ${ }^{17}$

La Constitución de la República del Ecuador ha establecido como piedras angulares de su bloque de constitucionalidad el derecho a la igualdad y no discriminación. De manera textual el artículo 11 ha definido que todas las personas son iguales y gozan de los mismos derechos, deberes y oportunidades; la discriminación de los mismos no deberá darse por cuestiones de sexo, identidad de género o cultural, entre otros. Es responsabilidad del Estado el establecimiento de acciones afirmativas que busquen el cumplimiento de los mismos. Ahora bien, ¿qué se entiende por acciones afirmativas? En este caso, las acciones afirmativas corresponden a las acciones de carácter temporal, encaminadas a eliminar la brecha de desigualdad y oportunidades ante la ley de unos con otros, ${ }^{18}$ que se puede dar por la creación de políticas públicas inclusivas, reformas legales, sentencias jurisprudenciales, entre otras formas de actuación de la institucionalidad estatal, que promuevan el reconocimiento de los derechos exigidos.

La igualdad es un concepto susceptible de una hermenéutica amplia, no obstante, tiene un aspecto objetivo que no puede ser obviado. En este caso, la igualdad en el sentido material tiene relación con obtener algo real que sea perceptible por los seres humanos como derechos, y el ejercicio de esos derechos como poder ejercer el voto, adquirir obligaciones o contraer matrimonio, ${ }^{19}$ equiparando esta línea horizontal de derechos y obligaciones de manera uniforme o igual entre los iguales y preservando la desigualdad en lo estrictamente desigual. ${ }^{20}$ Sin embargo, el sentido claro es que la búsqueda de la igualdad tiene un mandato constitucional que dispone al Estado el reconocimiento de una igualdad real o material, que debe ser protegida y reconocida para las personas que se encuentran en una situación de desigualdad, que, en este caso

17. Un ejemplo de estas distinciones son la Convención sobre la Eliminación de Todas las Formas de Discriminación contra la Mujer, de 1979 o la Convención Interamericana sobre la Protección de los Derechos Humanos de las Personas Mayores, entre otros más.

18. Wilson Castañeda, "Acción colectiva LGBT: Por el reconocimiento de la diversidad sexual y las identidades de género en el Caribe Colombiano", Cuadernos de literatura del Caribe e Hispanoamérica, n. ${ }^{\circ} 11$ (2010): 238-9.

19. Daniel Muñoz Cabrera, "Igualdad jurídica o igualdad material: ¿Qué va antes el huevo o la gallina?, Anuario de Derechos Humanos. Nueva Época, vol. 11 (2010): 406-10.

20. Ibíd., 415. Sobre este punto es relevante establecer que lo estrictamente desigual tiene que ver con las características autónomas que, bajo un estudio reflexivo, diferencian dos sujetos en un contexto determinado. 
concreto, son los seres humanos que forman parte de las poblaciones sexo-genéricas diversas.

La opinión consultiva reconoce que la igualdad respecto a los conceptos de orientación sexual y la identidad de género están protegidos y merecen el respeto como obligación legal, según los artículos 1.1 y 29 de la Convención Americana, los criterios de la Convención de Viena sobre el Derecho de los Tratados y las resoluciones de la Asamblea General de la Organización de los Estados Americanos. En consecuencia, ninguna práctica o decisión de derecho interno, sea esta ejecutada por autoridades estatales o particulares, puede disminuir o restringir de modo alguno los derechos de una persona basándose en cuestiones de orientación sexual, su identidad de género y/o su expresión de género. ${ }^{21}$ Es claro el mandato de la Corte IDH respecto a que en ningún caso el Estado tendrá, dentro de su ordenamiento jurídico interno, normativa tendiente a discriminar por cuestiones de orientación sexual o identidad de género, puesto que estos derechos son inherentes.

La igualdad, para que sea ejecutada, necesita enfrentar la exclusión existente mediante acciones afirmativas que permitan la inclusión, en este caso concreto, de los grupos sexo-genéricos diversos que sufren una discriminación histórica rodeada de rechazo y en algunas ocasiones de violencia. Es necesario que el Estado contrarreste esta realidad con un discurso común de igualdad en el que se superen atavismos retrógrados, se admita la tolerancia y respeto, tomando en cuenta que las transformaciones jurídicas deben incentivar las transformaciones sociales, ${ }^{22}$ y que es el deber del Estado regular y garantizar el derecho de todos sus ciudadanos sin importar las diversidades individuales que puedan tener sus habitantes.

Es fundamental el derecho a la igualdad en sus diferentes materias, sobre todo la igualdad en materia de sexualidad y sus diversidades, que, desde la perspectiva de los Derechos Humanos, no se encuentra sujeta a realización progresiva como sucede con los derechos económicos, sociales o culturales, sino que son derechos civiles de aplicación directa y de cumplimiento expedito por la institucionalidad estatal, sin limitación, ni traba alguna. ${ }^{23}$ El principio de no discriminación no solo aplica en el ámbito del reconocimiento de los derechos civiles, sino también respecto al matrimonio igualitario, y poder expresar de manera pública y reconocida por el Estado la decisión de dos personas -independientemente de su orientación sexual- de desarrollar su vida

21. Corte Interamericana de Derechos Humanos, Opinión consultiva OC-24/17 (24 de noviembre de 2017$), 41$.

22. Julia Flores Dávila, "La diversidad sexual y los retos de la igualdad y la inclusión", Consejo Nacional para Prevenir la Discriminación, n. ${ }^{\circ} 5$ (2007): 55-7.

23. Alda Facio, "El derecho a la igualdad entre hombres y mujeres", Corte Interamericana de Derechos Humanos, accedido 10 de febrero de 2019, 70-1, 〈http://www.corteidh.or.cr/tablas/a22083.pdf〉. 
y formar una familia, incluida en las diferentes esferas sociales como en el ámbito laboral, de esparcimiento, comercial, entre otros más.

La Ley Orgánica de Gestión de la Identidad y Datos Civiles,${ }^{24}$ muy cuestionada en sus diferentes artículos limitantes de derechos, establece en sus considerandos la normativa constitucional que reconoce la obligación del Estado de adoptar las medidas de acción afirmativa necesarias que promuevan la igualdad real a favor de los titulares de derechos que se encuentren en situación de desigualdad, basándose, sobre todo, en la igualdad de derechos y oportunidades de todos los integrantes de la sociedad. Eesta cuestión es contradictoria con la línea que sólidamente tiene la institucionalidad que gestiona las labores de registro civil, identificación y cedulación, y que, últimamente, ha tenido una postura clara en varios casos. ${ }^{25}$

El respeto, el cumplimiento y la promoción del derecho a la igualdad y no discriminación han sido ampliamente establecidos por el contexto del Derecho Internacional de los Derechos Humanos, y, por ende, en las diferentes vertientes de los derechos que en el ámbito político, social, económico y civil surgen o comparten la noción misma de igualdad. La norma constitucional y los instrumentos internacionales ratificados por el Ecuador, que se mencionaron, establecen que las normas relativas a la igualdad y no discriminación por su alcance no admiten restricciones en cuanto a raza, sexo, idioma y religión, como en el caso de la Carta de Naciones Unidas. ${ }^{26}$

\section{ANÁLISIS DE LA CORTE IDH SOBRE EL MATRIMONIO IGUALITARIO COMO DERECHO PROTEGIDO EN LA OC-24/17}

El matrimonio igualitario ha sido un tema de mucho debate en la región latinoamericana y ha puesto en discusión una serie de paradigmas importantes que tocan temáticas de índole religiosa, cultural, social, humana, legal, entre otras más, los cuales

24. En sus considerandos se establece que los artículos 11.12, 67, y 70 de la Constitución de la República del Ecuador deben ser respetados y fundamentan de manera vertebral la misma creación de la que emanan los artículos que se desarrollarán sobre la gestión de la identidad y datos civiles, rechazando las desigualdades y promoviendo el ejercicio sustancial de la igualdad en todos sus aspectos. Ecuador, Ley Orgánica de Gestión de la Identidad y Datos Civiles, Registro Oficial 684, 4 de febrero de 2016, 1.

25. El Registro Civil, Identificación y Cedulación ha mantenido una dura lucha para no reconocer el matrimonio igualitario en Ecuador, cuestión que es contradictoria en el ámbito de aplicación de las normas constitucionales y que ha sido revisado por la propia prensa. Mariela Rosero, "Dos parejas del mismo sexo esperan resultado de apelación a sentencia a favor de sus matrimonios en Cuenca", El Comercio, 5 de julio de 2018, párr. 2.

26. Anne Baysfsky, "El Principio de Igualdad y No Discriminación en el Derecho Internacional", Human Rights Law Journal, vol. 11, n. ${ }^{\circ}$ 1-2 (1990), 4-5. 
han sido el resultado de un esfuerzo activo de la población LGBTI. No obstante, existe un marco normativo importante en el ámbito internacional que respalda y reconoce el matrimonio igualitario como un derecho humano inherente a todas y todos, relacionado con el derecho a tener una familia y poder desarrollarse con libertad en búsqueda de la felicidad y seguridad en este camino que se llama "la vida". ${ }^{27}$

Los seres humanos somos libres de casarnos y fundar una familia, disfrutando de la igualdad de los derechos que se otorgan en el matrimonio hasta su disolución, tomando en cuenta que la familia es una parte importante de los seres humanos y la sociedad, ${ }^{28}$ cuestión fundamental que la Corte IDH empieza a utilizar como punto de partida en su argumentación de la opinión consultiva. Bajo la lógica de la Declaración Universal de los Derechos Humanos y el Pacto Internacional de Derechos Civiles y Políticos, establece que el matrimonio debe ser una opción libre que se determina por la autonomía pura de la libertad de las personas, siendo el Estado quien debe garantizar que el matrimonio se ejerza en un ámbito de igualdad de los contrayentes, tanto en sus derechos como en sus responsabilidades. ${ }^{29}$

Si revisamos la Declaración Americana de los Derechos y Deberes del Hombre, y la Convención Americana sobre Derechos Humanos, encontramos que se reconoce que todas las personas tienen derecho a constituir una familia, como un elemento fundamental de toda sociedad, $\mathrm{y}$, por lo tanto, a recibir protección de la misma por parte del Estado. ${ }^{30}$ Además, la Corte IDH pone en escena un análisis fundamental sobre el alcance del artículo 27 de la Convención Americana sobre Derechos Humanos, cuando se refiere al "derecho del hombre y la mujer a contraer matrimonio y fundar una familia", el cual muchas veces se interpreta de manera literal y restrictiva, sin embargo, en realidad el criterio del Tribunal es que esta formulación tampoco implica necesariamente que esa sea la única forma de familia protegida por la Convención, abriendo otros tipos de formas. ${ }^{31}$

En múltiples ocasiones se ha dispuesto que los diversos instrumentos internacionales de Derechos Humanos deben ser tomados en cuenta como cuerpos vivos que se adaptan a la evolución de los diversos tiempos, ${ }^{32}$ con la finalidad de que no exista

27. Guatemala Ministerio de Gobernación, ¿Qué son los Derechos Humanos? Evolución histórica (Ciudad de Guatemala: Ministerio de Gobernación, 1991), 16-9.

28. ONU Asamblea General, Declaración Universal de los Derechos Humanos, 10 de diciembre de 1948, art. 16.

29. ONU. Pacto Internacional de Derechos Civiles y Políticos, 19 de diciembre de 1976, art. 23.

30. Organización de los Estados Americanos, Declaración Americana de los Derechos y Deberes del Hombre, 30 de abril de 1948, art. 4.

31. Corte Interamericana de Derechos Humanos, Opinión Consultiva OC-24/17, 24 de noviembre de 2017, 75.

32. Como lo ha establecido la Corte Interamericana de Derechos Humanos, Opinión consultiva OC-16/99, 1 de octubre de 1999. 
una evidente exclusión de derechos, que es lo que ocurre en algunos países con las personas del mismo sexo que son privadas de su legítimo y legal derecho de poder contraer matrimonio y formar una familia. Por ende, cualquier limitación o práctica discriminatoria por parte del derecho interno de los países suscriptores no puede restringir o limitar estos derechos, si estos se fundamentan en la orientación sexual de las personas. ${ }^{33}$

Existen controversias sobre la aplicación de las opiniones consultivas expedidas por la Corte. En los pronunciamientos de la Corte IDH respecto a las opiniones consultivas que pudieren afectar los intereses de los Estados, debilitar o fortalecer la posición legal de un Estado en una controversia actual o futura, existe la oportunidad reglamentaria de hacerle saber a la Corte sus puntos de vista de las normas legales que van a ser interpretadas, es decir, existen mecanismos de participación ${ }^{34}$ y diferentes instrumentos que permiten escuchar posibles afectaciones. En el caso ecuatoriano, nuestro país es un Estado parte del Sistema Interamericano de Derechos Humanos, y está sometido a la jurisdicción de la Corte IDH, por lo que todo pronunciamiento es vinculante, incluyendo las interpretaciones realizadas por sus órganos rectores sobre la aplicación o el entendimiento de las normas vinculantes.

La Corte Interamericana desarrolla en la opinión consultiva un punto importante sobre "Los mecanismos por los cuales el Estado podría proteger a las familias diversas", en el que revisa los diferentes $\operatorname{casos}^{35} \mathrm{y}$ temáticas abordadas por los diferentes sistemas de Derechos Humanos, tanto regionales como universales, recogiendo los puntos más relevantes sobre este tema, lo cual plantea posibles dificultades aplicativas en los diferentes Estados para aceptar y cumplir con la protección de los derechos de las personas sexo-genéricas diversas que quisieran contraer matrimonio, y que son fruto de la evolución social, jurídica y cultural de los pueblos.

La Corte realiza un análisis histórico sobre las políticas públicas y los avances normativos de los diferentes Estados de la región. Uruguay desde el año 2007 estableció la unión concubina entre parejas del mismo sexo que terminó, en 2013, con el reconocimiento oficial del matrimonio entre parejas del mismo sexo; en el caso argentino, la ciudad de Buenos Aires autorizó la unión libre entre parejas del mismo sexo el año 2002, y desde 2010 es legal el matrimonio entre parejas del mismo sexo

33. Namiko Matzumoto y Luis Coronel, "El matrimonio entre personas del mismo sexo: ¿derecho humano o concesión graciosa de los tolerantes?", Revista Conflicto y Sociedad, vol. 1 (2013): 22-4.

34. Fabián Salvioli, "La competencia consultiva de la Corte Interamericana de Derechos Humanos marco legal y desarrollo jurisprudencial", Homenaje y Reconocimiento a Antonio Trinidad, tomo II (2004), 30.

35. La Corte Interamericana de Derechos Humanos recogió como base para emitir su criterio a los casos Duque vs. Colombia, Kramer vs. Austria, Kozac vs. Polonia, Vallianatos y Otros vs. Grecia, Oliari y Otros vs. Italia, entre otros. 
en toda la nación argentina; en Brasil el año 2011 el Supremo Tribunal Federal garantizó los mismos derechos a las parejas del mismo sexo que las heterosexuales, y, en 2013, el Consejo Nacional de Justicia estableció que no se puede negar el matrimonio o las uniones de hecho en parejas del mismo sexo, con base en el principio de no discriminación; Chile en 2015 estableció la unión civil entre parejas del mismo sexo; en Ecuador la unión de parejas del mismo sexo ha sido establecida desde 2014 mediante resolución del Registro Civil, y desde el año 2015 mediante reforma del Código Civil; en Colombia la Corte Constitucional reconoció el matrimonio entre parejas del mismo sexo señalando que la familia es un derecho que corresponde a todos sin discriminación. ${ }^{36}$

La Corte IDH también revisa las posturas conservadoras que evitan que se rompa con la discriminación y la limitación al derecho del libre desarrollo de la personalidad, sobre todo ante el argumento de que el matrimonio tiene un fin solamente reproductivo y que las uniones entre el mismo sexo no cumplirían este fin. Los jueces determinaron que esta afirmación no guarda relación alguna con el artículo 17 de la Convención, y que, de ser esta afirmación un argumento válido, seria discriminatorio para las parejas de sexos distintos que en el matrimonio no pueden procrear por cuestiones ajenas a su voluntad. Para terminar, la Corte establece que:

Los Estados deben garantizar el acceso a todas las figuras ya existentes en los ordenamientos jurídicos internos, para asegurar la protección de los todos los derechos de las familias conformadas por parejas del mismo sexo, sin discriminación con respecto a las que están constituidas por parejas heterosexuales. Para ello, podría ser necesario que los Estados modifiquen las figuras existentes, a través de medidas legislativas, judiciales o administrativas, para ampliarlas a las parejas constituidas por personas del mismo sexo. Los Estados que tuviesen dificultades institucionales para adecuar las figuras existentes, transitoriamente, $\mathrm{y}$ en tanto de buena fe impulsen esas reformas, tienen de la misma manera el deber de garantizar a las parejas constituidas por personas del mismo sexo, igualdad y paridad de derechos respecto de las de distinto sexo, sin discriminación alguna. ${ }^{37}$

Esto es determinante y de obligatorio cumplimiento de todos los Estados parte. Pensar más allá de las tradiciones y planteamientos provenientes de los sentimientos morales, y reconocer según nuestro estándar regional que existen otras formas distintas de matrimonios y familias debe ser el primer pensamiento cuando se discuten asuntos tan sensibles como este.

36. Corte Interamericana de Derechos Humanos, Opinión Consultiva OC-24/17, 24 de noviembre de 2017, $80-5$.

37. Ibíd., 86-7. 


\section{CONCLUSIÓN}

Para terminar, creo que es pertinente mencionar tres puntos importantes respecto a los aportes de la opinión consultiva OC-24/17 que nos traen a la reflexión. El primero trata sobre el matrimonio como institución jurídica que se ha desarrollado en el tiempo; el segundo tiene que ver cómo la igualdad y no discriminación son imperativos de gran valor en relación con las personas sexo-genéricas diversas; y el tercero tiene que ver con la disposición clara para los Estados, por parte de la Corte IDH, que establece como estándar regional la igualdad y no discriminación en instituciones como la familia y el matrimonio, bajo la interpretación de los diferentes instrumentos de Derechos Humanos.

Una vez revisada la normativa anterior en materia penal sobre la libertad sexual, es triste pero valioso reconocer que fue a finales del siglo XX que se declaró la inconstitucionalidad de la tipificación del artículo 516 del anterior Código Penal, el cual reprimió la homosexualidad como un delito más. Es valioso porque el reconocimiento de las falencias por parte del Estado permite que la estructura normativa vaya permeabilizándose frente a las libertades y la promoción de derechos de la ciudadanía, en este caso, incluyendo las minorías. Fueron las múltiples movilizaciones sociales lideradas por las primeras organizaciones LGBTI las que denunciaron la injusta criminalización de las personas sexo-genéricas diversas en el ámbito nacional e internacional.

En el segundo punto, queda en evidencia, tras la revisión de los diferentes instrumentos internacionales de Derechos Humanos y por la argumentación de la Corte, que el derecho a la igualdad y no discriminación son puntos fundamentales reconocidos por los Estados parte, que no excluyen a los derechos referentes a las personas sexo-genéricas diversas. Por lo tanto, se debe reconocer tanto en la normativa local y en la aplicación de las diferentes políticas públicas de los Estados el velar por el cumplimiento de políticas públicas diversas, y rechazar la discriminación y el trato diferenciado a las personas que tienen una identificación sexual diferente a la establecida como "regular".

Por último, la Corte en su opinión consultiva establece un estándar regional importante que guarda relación con el derecho civil del matrimonio, el cual debe ser interpretado de manera integral y progresiva en materia de Derechos Humanos. Esto quiere decir que el derecho al matrimonio aplica sin distinción o discriminación para personas sexo-genéricas diversas y dispone a todos los Estados parte la obligación de respetar y generar las respectivas medidas para garantizar el reconocimiento y alcance de este derecho a sus ciudadanos. 
Aún queda mucho trabajo por delante para que se dé materialmente el efectivo cumplimiento de los alcances que estableció la opinión consultiva OC-24/17. Es un trabajo arduo que conlleva la responsabilidad tanto de la academia como de los servidores públicos, para que no se menoscaben los derechos que tienen las personas sexo-genéricas diversas en todos los ámbitos. A pesar de que existe la Sentencia n. ${ }^{\circ}$ 11-18-CN/19 que reconoce el matrimonio igualitario, el proceso de sensibilización social y de informar de manera eficaz a la ciudadanía, y en especial a los sectores más conservadores y reaccionarios, está pendiente debiendo ser un trabajo sistemático y multisectorial liderado por el Estado.

\section{BIBLIOGRAFÍA}

Aguiar Román, Javier. "Historia legal de la homosexualidad en el Ecuador". Revista Novedades Jurídicas n. ${ }^{\circ} 146$ (2018).

Barrero, Abraham. "El matrimonio entre ciudadanos del mismo sexo: ¿Derecho fundamental u opción legislativa?”. Revista de Estudios Politicos. Nueva Época, n. 163 (2014).

Baysfsky, Anne. "El principio de igualdad y no discriminación en el derecho internacional". Human Rights Law Journal. Vol. 11, n. ${ }^{\circ} 1-2$ (1990).

Castañeda, Wilson. “Acción colectiva LGBT: Por el reconocimiento de la diversidad sexual y las identidades de género en el Caribe Colombiano". Cuadernos de literatura del Caribe e Hispanoamérica, . $^{\circ} 11$ (2010).

Consejo de Derechos Humanos de las Naciones Unidas. "Principios de Yogyakarta". Panel Internacional de Especialistas en Legislación Interna de Derechos Humanos y Orientación Sexual e Identidad de Género. 26 de marzo de 2007. 〈http://www.oas.org/dil/esp/orientacion_sexual_Principios_de_Yogyakarta_2006.pdf〉.

Corte Interamericana de Derechos Humanos. Opinión consultiva OC-24/17. 24 de noviembre de 2017.

—. Opinión consultiva OC-16/99. 1 de octubre de 1999.

Donoso Loor, Andrés. "Convocan nuevas marchas contra el matrimonio civil igualitario en Ecuador”. El Universo. 19 de junio del 2019.

Ecuador. Constitución de la República del Ecuador. Registro Oficial 1, 11 de agosto de 1998.

-. Constitución de la República del Ecuador. Registro Oficial 449, 20 de octubre de 2008.

- Ley Orgánica de Gestión de la Identidad y Datos Civiles. Registro Oficial 684, 4 de febrero de 2016.

Ecuador. Corte Constitucional. "Sentencia". En Caso n. ${ }^{\circ} 11-18-C N .12$ de junio de 2019.

El Diario. "Cuando ser gay era un delito". El Diario. 5 de diciembre de 2017.

El Telégrafo. "Homosexualidad era castigada con 8 años de prisión en década del 90”. El Telégrafo. 2 de diciembre de 2016. 
Facio, Alda. "El derecho a la igualdad entre hombres y mujeres". Corte Interamericana de Derechos Humanos. Accedido 10 de febrero de 2019. 〈http://www.corteidh.or.cr/tablas/ a22083.pdf».

Flores Dávila, Julia. "La diversidad sexual y los retos de la igualdad y la inclusión". Consejo Nacional para Prevenir la Discriminación, n. 5 (2007).

Guatemala Ministerio de Gobernación. ¿Qué son los derechos humanos? Evolución histórica. Ciudad de Guatemala: Ministerio de Gobernación, 1991.

Matzumoto, Namiko, y Luis Coronel. "El matrimonio entre personas del mismo sexo: ¿derecho humano o concesión graciosa de los tolerantes?". Revista Conflicto y Sociedad. Vol. 1 (2013).

Muñoz Cabrera, Daniel. "Igualdad jurídica o igualdad material: ¿Qué va antes el huevo o la gallina?”. Anuario de Derechos Humanos. Nueva Época. Vol. 11 (2010).

Nikken, Pedro. "La protección de los derechos humanos: haciendo efectiva la progresividad de los derechos económicos, sociales y culturales". Revista IIDH. Vol. 5 (2010).

ONU Asamblea General. Pacto Internacional de Derechos Civiles y Politicos. 19 de diciembre de 1976.

—.Declaración Universal de los Derechos Humanos. 10 de diciembre de 1948.

Organización de los Estados Americanos. Declaración Americana de los Derechos y Deberes del Hombre. 30 de abril de 1948.

Rosero, Mariela. "Dos parejas del mismo sexo esperan resultado de apelación a sentencia a favor de sus matrimonios en Cuenca". El Comercio. 5 de julio de 2018.

Salvioli, Fabián. "La competencia consultiva de la Corte Interamericana de Derechos Humanos marco legal y desarrollo jurisprudencial". Homenaje y Reconocimiento a Antonio Trinidad, tomo II (2004). 